DOI: $10.12957 /$ demetra.2015.16010

\title{
Qualidade higiênico-sanitária de sorvetes tipo italiano e de massa (artesanal e industrializado) comercializados na região noroeste do Rio Grande do Sul, Brasil
}

\author{
Sanitary-higienic conditions of italian style and pasta (artisanal and industrial) ice cream \\ marketed in the northwest region of Rio Grande do Sul, Brazil
}

\author{
Juliana Raquel da Silva Damer \\ Viviane Garcia ${ }^{2}$ \\ Aldoir Almeida Gusmão ${ }^{3}$ \\ Terimar Ruoso Moresco ${ }^{4}$ \\ 1 Universidade Federal de Santa Maria, \\ Departamento de Análises Clínicas e \\ Toxicológicas, Programa de Pós-graduação em \\ Ciências Farmacêuticas. Santa Maria-RS, Brasil. \\ ${ }^{2}$ Universidade Federal de Santa Maria, \\ Laboratório de Biologia. Santa Maria-RS, Brasil. \\ ${ }^{3}$ Universidade Federal de Santa Maria, Hospital \\ Universitário de Santa Maria. Santa Maria-RS, \\ Brasil. \\ ${ }^{4}$ Universidade Federal de Santa Maria, \\ Departamento de Ciências da Saúde. Santa \\ Maria-RS, Brasil. \\ Correspondência / Correspondence \\ Juliana Raquel da Silva Damer \\ E-mail: juliana_damer@yahoo.com.br
}

\section{Resumo}

Objetivou-se avaliar a qualidade microbiológica de sorvetes comercializados no Noroeste do Rio Grande do Sul, Brasil. As amostras foram submetidas às análises: estimativas em Número Mais Provável (NMP/g) de coliformes totais, coliformes termotolerantes, Escherichia coli, pesquisa da presença de Salmonella spp., contagem em unidades formadoras de colônia (UFC/g) de Staphyococcus coagulase positiva, mesófilos e psicrotrófilos aeróbios totais, além da investigação das características morfotintoriais de colônias provenientes da contagem de psicrotrófilos. Foram analisadas 21 amostras de sorvete, sendo sete de sorvete tipo italiano, sete de sorvete de massa artesanal e sete de sorvete de massa industrializado, provenientes de diferentes locais. Coliformes termotolerantes foram encontrados acima dos valores estabelecidos pela legislação em $28,6 \%$ de ambos os sorvetes de massa. E. coli foi encontrada em $42,8 \%$ e $14,3 \%$ dos sorvetes de massa artesanal e industrializado, respectivamente. Salmonella spp. e Staphylococcus coagulase positiva não foram detectados.Todas as amostras de sorvete tipo italiano apresentaram contagens elevadas de mesófilos, diferindo significativamente dos sorvetes de massa industrializados, porém não dos artesanais. Altas contagens de psicrotrófilos também foram encontradas em sorvetes tipo italiano, diferindo significativamente de ambos os sorvetes de massa. Bastonetes gram negativos predominaram entre os psicrotrófilos. Os resultados indicaram possíveis falhas higiênicas durante a produção e/ou armazenamento dos sorvetes. Assim, faz-se necessário maior fiscalização nos pontos de venda e na 
produção de sorvetes, principalmente através de treinamentos quanto às Boas Práticas. Atenção especial deve ser dada para os sorvetes artesanal e italiano, pois os fabricantes não seguem um processo padrão de produção.

Palavras-chave: Sorvetes. Alimentos. Bactérias. Microbiologia de Alimentos. Manipulação de Alimentos.

\section{Abstract}

The article aimed to evaluate the microbiological quality of ice cream sold in the Northwest Rio Grande do Sul, Brazil. The samples were submitted to analysis: estimates Most Probable Number (MPN/g) of total coliforms, fecal coliforms, Escherichia coli, Salmonella spp. search, counting colony forming units (CFU/g) of Staphyococcus coagulase positive, mesophilic and total aerobic psychrotrophs, beyond the investigation of morphotinctorial characteristics of colonies from psychrotrophs count. Samples of 21 ice cream types, seven of Italian style ice cream, seven handmade dough ice cream and seven industrialized mass of ice cream, from different Locations. Fecal coliforms were found above the values established by legislation in $28.6 \%$ of both mass ice cream. E. coli was found in $42.8 \%$ and $14.3 \%$ of handmade dough ice cream and industrialized, respectively. Salmonella spp. and Staphylococcus coagulase positive were detected. All Italian style ice cream samples showed high counts of mesophilic, differing significantly from the industrialized mass ice cream, but not the craft. High psychrotroph counts were also found in Italian style ice cream, differing from both mass ice cream. Gram negative rods predominated among psychrotrophs. The results indicate possible poor hygiene during production and/or storage of the ice cream. Thus, increased enforcement necessary to make the point of sale and production of ice cream, mainly through training for the Good Practice. Special attention should be given to the artisanal and Italian ice cream, because manufacturers do not follow a standard production process.

Key words: Ice Cream. Foods. Bacterias. Food Microbiology. Food Handling. 


\section{Introdução}

O sorvete é uma emulsão de gordura e proteínas ou uma mistura de água, açúcar e outros ingredientes que são submetidos ao congelamento. São considerados alimentos completos e de alto valor energético. Quando se utiliza leite no seu preparo, são constituídos de $10 \%$ de gordura, $20 \%$ de sólidos totais, vitaminas A, B, C, D, E, K e os minerais cálcio e fósforo. ${ }^{1}$ Possuem ainda 12-17\% de carboidratos, 55-65\% de água e 0,2-0,5\% de emulsificantes e estabilizantes. ${ }^{2}$ Por ser uma matriz inovadora e bem aceita pela população, pesquisas têm sido realizadas para incorporar microrganismos vivos (probióticos), em dosagens adequadas ao benefício da saúde, principalmente para a microbiota gastrintestinal, como por exemplo, espécies de Lactobacillus que contribuem para melhorar suas características nutricionais e funcionais. ${ }^{1,3,4}$

Para manter tais características e evitar a degradação do produto, a Agência Nacional de Vigilância Sanitária (ANVISA) recomenda que os sorvetes, quando produzidos com leite e ovos, sejam obrigatoriamente pasteurizados. ${ }^{5}$ Entretanto, esse processo não é realizado nos sorvetes caseiros, e embora seja utilizado leite pasteurizado, esterilizado ou leite em pó, contaminações após o preparo podem acontecer, transformando esse alimento em potencial veiculador de patógenos. ${ }^{6,7}$ A pasteurização do leite é um tratamento térmico brando e não recupera matéria-prima de má qualidade ${ }^{8}$ sendo ela diretamente proporcional à qualidade microbiológica do produto acabado. ${ }^{9}$

Segundo a legislação brasileira, os sorvetes se enquadram no grupo dos gelados comestíveis e devem ser parcial ou totalmente congelados para garantir sua estabilidade durante o transporte e armazenamento. ${ }^{10} \mathrm{O}$ congelamento dos alimentos tem por finalidade prolongar a vida de prateleira, mas alguns microrganismos podem se desenvolver mesmo nos produtos conservados em temperaturas próximas ou inferiores a $0^{\circ} \mathrm{C} .{ }^{11}$ Para Kanbakan et al., ${ }^{12}$ o método de resfriamento do sorvete, quando não eficiente, leva ao aumento da contagem de microrganismos no produto final em relação às matérias-primas.

A contaminação microbiana dos alimentos pode ocorrer de maneira direta, através da matériaprima contaminada, ou indireta, através do manipulador, sobretudo quando este possui más condições de higiene. ${ }^{6}$ Microrganismos presentes na pele sadia, nariz, mãos, fezes humanas e animais ou feridas de pele são frequentemente encontrados em alimentos deteriorados ou que causaram toxinfecções. ${ }^{11}$ Kanbakan et al. ${ }^{12}$ detectaram coliformes termotolerantes nas mãos de trabalhadores do setor de venda de sorvetes, ou seja, na fase de entrega do produto final ao consumidor.

Casos de enfermidades relacionadas ao consumo de sorvetes contaminados com microrganismos ou suas toxinas já foram relatados, sobretudo as causadas por Salmonella spp., Staphylococcus aureus, formadores de toxinas, Shigella spp. e cepas enteropatogênicas de Escherichia coli. ${ }^{6,11}$ 
A Organização Mundial ds Saúde (OMS) afirma que doenças alimentares com sintomas gastrintestinais são um problema de saúde pública em todo o mundo e resultam da ingesta de alimentos contaminados com microrganismos na fase produtiva ou de consumo, podendo resultar de contaminação ambiental da água, solo e ar. ${ }^{13}$

Para minimizar ou até mesmo eliminar esses problemas, indústrias alimentícias têm implementado o Sistema de Análises de Perigos e Pontos Críticos de Controle (APPCC). Com a utilização desse sistema, uma indústria de sorvetes foi capaz de reduzir de 20 a $35 \%$ das contagens de coliformes totais e mesófilos, demonstrando que o controle higiênico e dos processos de pasteurização e congelamento são essenciais para obter um produto de qualidade. ${ }^{14}$

Embora as falhas que podem ocorrer durante a produção sejam importantes, os maiores índices de contaminação acontecem através da manipulação inadequada do produto nos pontos de venda. A higienização incorreta das mãos dos manipuladores e a água em que a colher para servir o sorvete é mantida representam as principais fontes de contaminação. ${ }^{12}$

Segundo, Kokkinakis et al., ${ }^{14} \mathrm{em}$ trabalho que avaliou todo o processo produtivo, as Boas Práticas de Fabricação e Boas Práticas de Higiene estão associadas à ausência de $S$. aureus e coliformes totais, bem como de E. coli. Nesse contexto, o presente estudo teve por objetivo investigar a qualidade higiênico-sanitária de diferentes tipos de sorvetes, como produto final, comercializados na região Noroeste do Rio Grande do Sul, Brasil.

\section{Metodologia}

Durante os meses de dezembro de 2012 a julho de 2013, foram coletadas 21 amostras de sorvete, sendo sete de sorvete tipo italiano, sete de sorvete de massa artesanal e sete de sorvete de massa industrializado, todos provenientes de diferentes pontos de venda. As amostras, depois de adquiridas como sendo para consumo, foram imediatamente acondicionadas em caixas isotérmicas e transportadas até o Laboratório de Microbiologia da Universidade Federal de Santa Maria, Palmeira das Missões, Rio Grande do Sul.

As estimativas em número mais provável $(\mathrm{NMP} / \mathrm{g})$ de coliformes totais, coliformes termotolerantes e de Escherichia coli, bem como a pesquisa da presença de Salmonella spp. em $25 \mathrm{~g}$ e as contagens em unidades formadoras de colônia (UFC/g) de Staphylococcus coagulase positiva, mesófilos e psicrotrófilos aeróbios totais obedeceram às metodologias descritas pela American Public Health Association. ${ }^{15}$ Características morfotintoriais de microrganismos psicrotrófilos oriundos de cinco colônias de aspectos macroscópicos diferentes de cada amostra foram determinadas pelo método de Gram. 
Os valores das contagens de microrganismos encontrados nos diferentes tipos de sorvetes foram transformados em log na base 10. A frequência das variáveis paramétricas é apresentada como média \pm desvio padrão (DP) e foram analisadas por ANOVA de 1-via. Dados não paramétricos foram submetidos à análise por Kruskal-Wallis e estão apresentados como mediana e percentis. Na comparação dos grupos, foi utilizado teste de Tukey. Em todas as análises, foi considerado um nível de significância de $\mathrm{p}<0,05$. Os testes foram realizados através do tipo italianoware SigmaPlot 11.0 ${ }^{\circledR}$ (Systat Tipo italianoware, Inc. SigmaPlot for Windows).

\section{Resultados}

Na tabela 1 estão descritos os resultados das análises microbiológicas realizadas nos três tipos de sorvetes comercializados na região Noroeste do Rio Grande do Sul.

Tabela 1. Resultados das análises microbiológicas realizadas em sorvetes comercializados no noroeste do Rio Grande do Sul, Brasil, 2013.

\begin{tabular}{|c|c|c|c|c|}
\hline Microrganismo & $\mathrm{SI}(\mathrm{n}=7)$ & SMA $(n=7)$ & $\operatorname{SMI}(n=7)$ & Total $(n=21)$ \\
\hline Mesófilos (UFC/g) & $\begin{array}{c}2,1 \times 10^{4}-2,5 \\
\times 10^{6}\end{array}$ & $\begin{array}{l}1,8 \times 10^{4}- \\
3,1 \times 10^{6}\end{array}$ & $\begin{array}{c}<10,0-2,4 \times \\
10^{5}\end{array}$ & $\begin{array}{c}<10,0-3,1 \times \\
10^{6}\end{array}$ \\
\hline Psicrotrófilos (UFC/g) & $\begin{array}{c}2,7 \times 10^{4}-1,0 \\
\times 10^{7}\end{array}$ & $\begin{array}{c}<10,0- \\
8,0 \times 10^{6}\end{array}$ & $\begin{array}{c}<10,0-5,8 \\
10^{5}\end{array}$ & $\begin{array}{c}<10,0-1,0 \times \\
10^{7}\end{array}$ \\
\hline Coliformes $35^{\circ} \mathrm{C}(\mathrm{NMP} / \mathrm{g})$ & $<3,0-460$ & $3,6->1.100$ & $<3,0-1.100$ & $<3,0->1.100$ \\
\hline Coliformes $45^{\circ} \mathrm{C}(\mathrm{NMP} / \mathrm{g})$ & $<3,0$ & $<3,0-460$ & $<3,0-1.100$ & $<3,0-1.100$ \\
\hline Escherichia coli $(\mathrm{NMP} / \mathrm{g})$ & $<3,0$ & $<3,0-15$ & $<3,0-93$ & $<3,0-93$ \\
\hline $\begin{array}{l}\text { Salmonella spp. (presença/ } \\
\text { ausência) }\end{array}$ & Ausência & Ausência & Ausência & Ausência \\
\hline $\begin{array}{l}\text { Staphylococcus coagulase } \\
\text { positiva (UFC/g) }\end{array}$ & $<100$ & $<100$ & $<100$ & $<100$ \\
\hline
\end{tabular}

SI: sorvete tipo italiano

SMA: sorvete de massa artesanal

SMI: sorvete de massa industrializado 
Quanto às estimativas de coliformes totais, 54,2\%, 71,4\% e 71,4\% dos sorvetes tipo italiano, de massa artesanal e industrializado estavam contaminados com tais bactérias, respectivamente; $28,6 \%$ de ambos os sorvetes de massa apresentaram coliformes termotolerantes acima de $50 \mathrm{NMP} / \mathrm{g}$. Já os sorvetes tipo italiano apresentaram estimativas abaixo deste valor para esses microrganismos. A presença de E. coli foi detectada em 42,8\% e 14,3\% das amostras de sorvetes de massa artesanal e industrializado, respectivamente (figura 1).

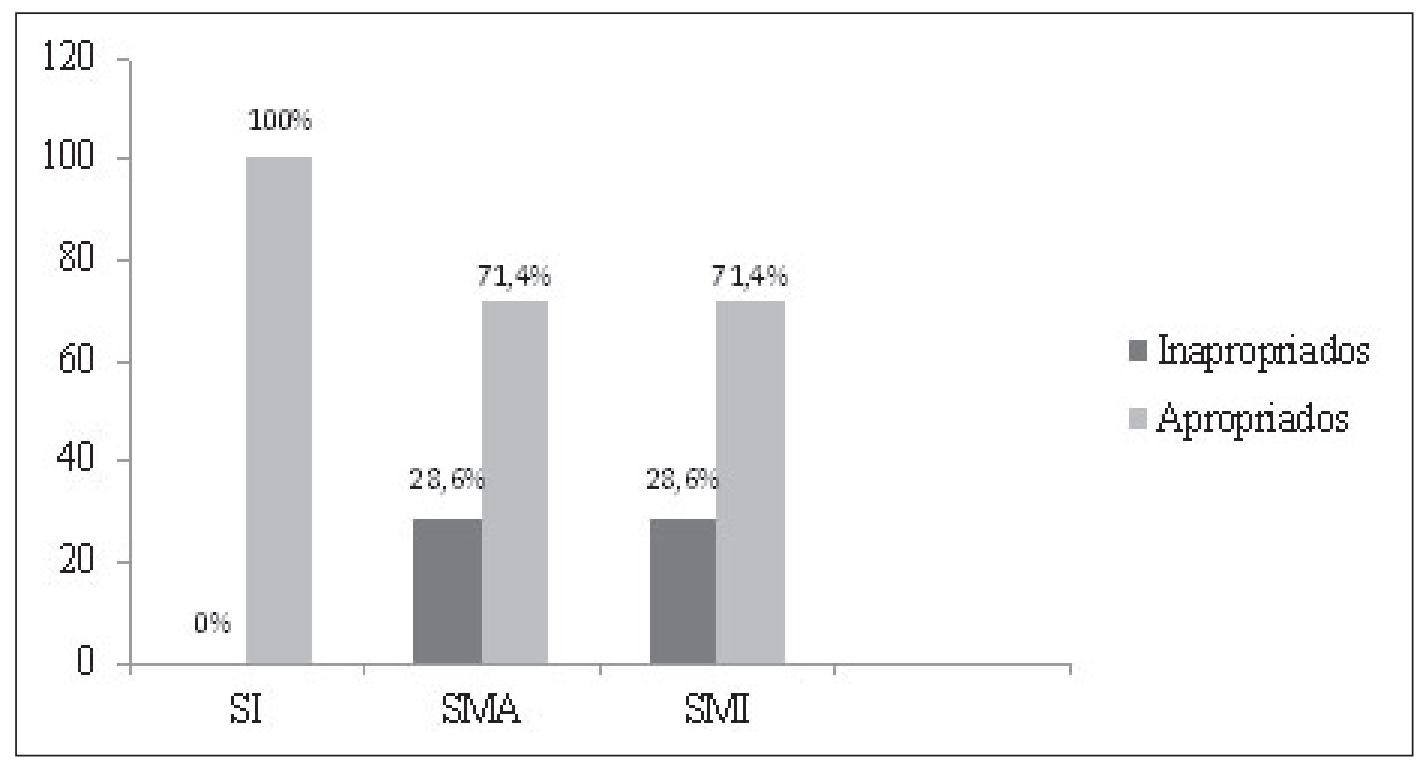

SI: sorvete tipo italiano

SMA: sorvete de massa artesanal

SMI: sorvete de massa industrializado

Figura 1. Percentual de sorvetes apropriados e inapropriados para consumo humano de acordo com os padrões microbiológicos estabelecidos pela RDC 12 de $2001^{14}$. Noroeste do Rio Grande do Sul, Brasil, 2013.

Salmonella spp. e Staphylococcus coagulase positiva não foram detectados nas amostras analisadas. 
As contagens de mesófilos nos sorvetes tipo italiano não diferiram significativamente dos sorvetes de massa artesanal, mas diferiram dos industrializados. Já a contaminação em sorvetes de massa artesanal foi superior à obtida em sorvetes industrializados, mas não diferiram significativamente entre si (tabela 2).

Tabela 2. Contagem de bactérias mesófilas e psicrotrófilas em sorvetes comercializados no noroeste do Rio Grande do Sul, Brasil, 2013

\begin{tabular}{|c|c|c|c|}
\hline \multicolumn{4}{|c|}{ Tipo de sorvete } \\
\hline & SI & SMA & SMI \\
\hline $\begin{array}{l}\text { Mesófilos }{ }^{1,3} \\
(\log \mathrm{UFC} / \mathrm{g}) \\
\text { média } \pm \mathrm{DP}\end{array}$ & $5,40 \pm 0,78^{\mathrm{A}}$ & $4,91 \pm 0,88^{\mathrm{AB}}$ & $3,57 \pm 1,59^{\mathrm{B}}$ \\
\hline \multirow{2}{*}{$\begin{array}{c}\text { Psicotrófilos } \\
(\log \mathrm{UFC} / \mathrm{g}) \\
\text { mediana }(\mathrm{P} 25-\mathrm{P} 75)\end{array}$} & $\begin{array}{l}\text { Tipo italiano } \\
\text { (mediana) }\end{array}$ & Artesanal (mediana) & $\begin{array}{c}\text { Industrializado } \\
\text { (mediana) }\end{array}$ \\
\hline & $6,15^{\mathrm{C}}(5,13-6,54)$ & $1,00^{\mathrm{DE}}(1,00-3,99)$ & $1,00^{\mathrm{E}}(1,00-3,77)$ \\
\hline
\end{tabular}

SS: sorvete tipo italiano

SMA: sorvete de massa artesanal

SMI: sorvete de massa industrializado

${ }^{1}$ Valores nas linhas, seguidos de letras desiguais diferem pelo teste de Tukey $(\mathrm{P}=0,02)$.

${ }^{2}$ Valores nas linhas, seguidos de letras desiguais diferem pelo teste de Tukey $(\mathrm{P}=0,07)$.

${ }^{3}$ Logaritmos do número de unidades formadoras de colônias/g de sorvete.

Amostras de sorvetes de massa, 57\% dos artesanais e 71,4\% dos industrializados não apresentaram crescimento de psicrotrófilos aeróbios totais (tabela 1). Já os sorvetes tipo italiano apresentaram maiores contagens para estes microrganismos, diferindo estatisticamente de ambos os sorvetes de massa (tabela 2).

As características morfotintoriais dos microrganismos psicrotrófilos aeróbios totais pela coloração de Gram podem ser observados na figura 2. 


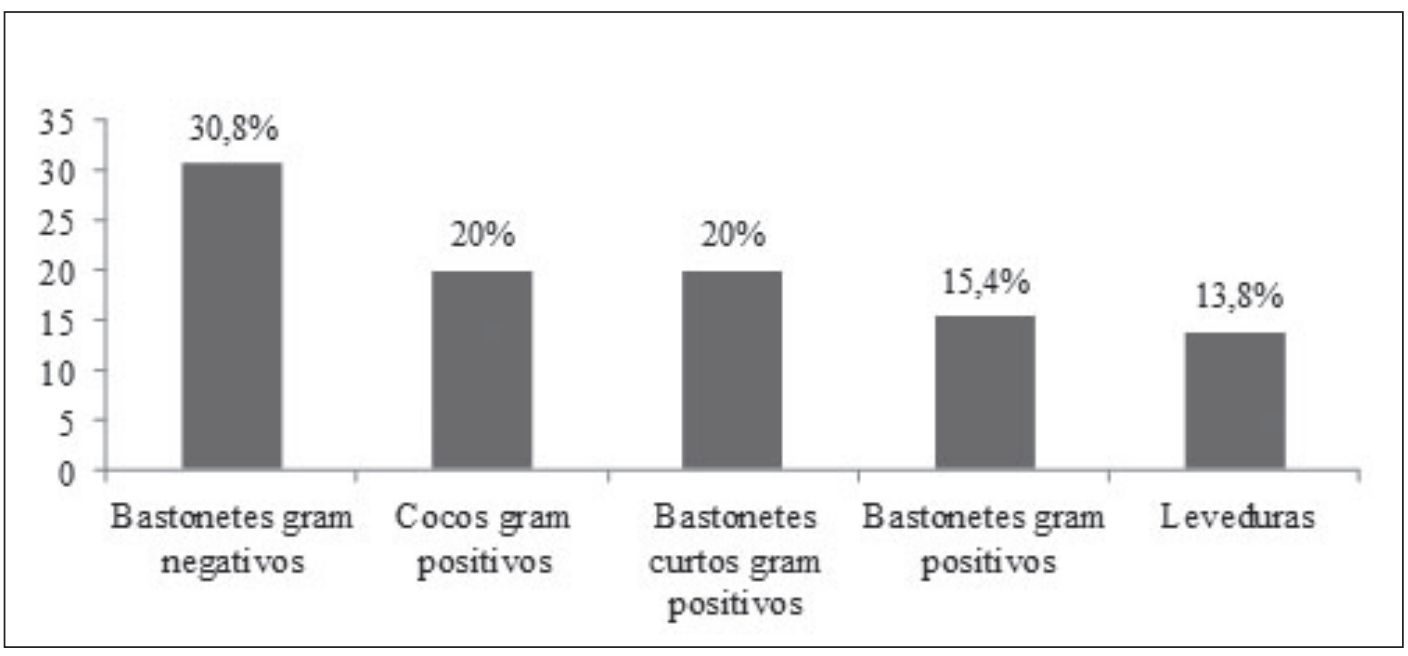

Figura 2. Características morfotintoriais de microrganismos psicrotrófilos presentes nas amostras dos três tipos de sorvetes, $n=65$ esfregaços. Noroeste do Rio Grande do Sul, Brasil, 2013.

\section{Discussão}

Segundo a Resolução da Diretoria Colegiada (RDC) no $12,{ }^{16}$ os gelados comestíveis podem ser consumidos com segurança quando as estimativas para coliformes termotolerantes forem menores que $50 \mathrm{NMP} / \mathrm{g}$, a contagem de Staphylococcus coagulase positiva menor que $500 \mathrm{UFC} / \mathrm{g}$ e na ausência do patógeno Salmonella spp. em 25g.

As estimativas de coliformes totais obtidas nos três tipos de sorvetes analisados revelaram que mais da metade das amostras estavam contaminadas, independentemente do tipo de sorvete. Estimativas ou contagens deste grupo de bactérias nos alimentos não são exigidas pela legislação brasileira; entretanto, sua pesquisa é importante, pois indica recontaminação durante as etapas de produção. ${ }^{17}$

Os sorvetes de massa apresentaram grande contaminação com coliformes termotolerantes, estando 28,6\% das amostras de ambos os grupos impróprios para consumo humano, pois ultrapassaram o limite tolerável preconizado pela legislação brasileira. ${ }^{16}$

Já os sorvetes tipo italiano apresentaram-se todos com estimativas para coliformes termotolerantes dentro dos padrões estabelecidos pela legislação brasileira. ${ }^{16}$ No entanto, a conformidade com a legislação não significa ausência de outros microrganismos potencialmente patogênicos ou processo 
de deterioração, pois mesmo dentro dos padrões de consumo, essas amostras apresentaram os maiores índices de contaminação por microrganismos mesófilos e psicrotrófilos.

A espécie E. coli foi detectada em ambos sorvetes de massa e, dentre eles, o sorvete de massa industrializado apresentou os maiores valores de NMP/g. Já o sorvete de massa artesanal apresentou o maior número de amostras contaminadas. A presença desta bactéria está ligada à falha na higienização em alguma etapa que antecede o consumo, pois está presente na microbiota intestinal de animais de sangue quente. É importante ressaltar que algumas linhagens de E. coli causam enfermidades gastrointestinais com elevada gravidade. ${ }^{6}$

Schrijver et al. ${ }^{7}$ relataram que cepas de E. coli produtoras de verotoxina foram capazes de causar diarreia severa e síndrome hemolítica urêmica em crianças que haviam ingerido sorvete. Os autores sugeriram que, possivelmente, ocorreu contaminação cruzada durante a manipulação, após a pasteurização do leite, pois cepas idênticas também foram isoladas de fezes de bezerros e da palha da fazenda.

Em estudo semelhante realizado na Turquia, sorvetes envasados não apresentaram contaminação por coliformes nem por E. coli, diferindo dos sorvetes não envasados, os quais $50,1 \%$ e $63,6 \%$ apresentaram-se fora dos padrões locais estabelecidos para tais microrganismos, respectivamente. ${ }^{18}$ Resultados similares foram obtidos no Egito, ${ }^{19}$ onde $55 \%, 43,7 \%$ e $57 \%$ dos sorvetes analisados estavam com valores inaceitáveis para coliformes totais, coliformes termotolerantes e E. coli, respectivamente. Menores índices de contaminação foram obtidos na Turquia por Yaman et al..$^{20}$ e por Rizzo-Benato \& Gallo21, no Brasil.

Em nosso trabalho, nenhuma amostra de sorvete apresentou-se contaminada com o patógeno Salmonella spp., responsável por surtos de toxinfecções graves pela ingestão de alimentos de origem animal contaminados, principalmente derivados de carnes, ovos, aves e leite, ${ }^{22}$ incluindo sorvetes. 23,24,25 Assim, todas as amostras estavam apropriadas para consumo de acordo com a legislação brasileira. ${ }^{16}$ Este resultado corrobora os obtidos por Pazianotti et al.${ }^{26}$ e Pooran et al.,${ }^{27}$ mas difere dos apresentados por Yaman et al., ${ }^{20}$ Queiroz et al. ${ }^{2}$ e Ambily \& Beena, ${ }^{28}$ os quais identificaram Salmonella spp. em 6,8\%,75\% e 3,7\% das amostras de sorvete analisadas, respectivamente. Rosa et al. ${ }^{9}$ encontraram este patógeno na matéria-prima e nos respectivos sorvetes industrializados, além de problemas quanto às Boas Práticas de Fabricação, confirmando que as falhas durante o processamento e na escolha da matéria-prima são refletidas diretamente na qualidade do produto final.

Nenhuma das amostras analisadas apresentou contaminação por Staphylococcus coagulase positiva, estando todas de acordo com os padrões estabelecidos pela RDC n⿳0 $12^{16}$ neste aspecto. Dentre essas bactérias, o $S$. aureus é o mais importante em nível clínico, pois está associado a doenças veiculadas por alimentos devido à produção de enterotoxinas que provocam surtos de intoxicação 
alimentar, sobretudo pelo consumo de leite e derivados lácteos contaminados. ${ }^{11}$ Ele está presente nas cavidades nasais, garganta e pele, além de ser frequentemente encontrado em amostras de leite. ${ }^{6} \mathrm{O}$ fato de esta bactéria não ter sido detectada nos sorvetes analisados pode estar relacionado ao correto processo de pasteurização associado à boa qualidade do leite. Este resultado corrobora os obtidos por Vica et al. ${ }^{29}$ mas diverge dos obtidos por El-Sharef et al. ${ }^{30} \mathrm{e}$ Ambily \& Beena..$^{28}$

Embora os sorvetes de massa artesanal estivessem mais contaminados com mesófilos, não diferiram significativamente dos industrializados. Isto pode ter ocorrido pelo fato de a temperatura de armazenamento impedir o crescimento da maioria dos microrganismos. Pooran et al. ${ }^{27}$ encontraram diferença significativa entre os sorvetes industrializados e os caseiros, pois nos últimos as contagens de mesófilos foram sempre mais elevadas. El-Sharef et al. ${ }^{30}$ também obtiveram contagens elevadas, variando de $10^{2}$ a $10^{8}$ para sorvetes abertos e de $10^{1}$ a $10^{8}$ para sorvetes envasados. Azadnia et al. ${ }^{31}$ encontraram média elevada para contagem de mesófilos $\left(10^{6}\right)$, dos quais $88 \%$ dos sorvetes apresentaram-se fora dos padrões estabelecidos pela legislação local. Movassagh et al. ${ }^{32}$ encontraram resultados semelhantes em sorvetes comercializados no Irã.

Os sorvetes tipo italiano foram os mais contaminados com psicrotrófilos, diferindo estatisticamente de ambos os sorvetes de massa. Isso pode ter ocorrido devido às diferenças de temperatura de armazenamento, pois os sorvetes de massa são armazenados em temperatura de $-18^{\circ} \mathrm{C}$ e os sorvetes tipo italiano em temperaturas próximas a $0^{\circ} \mathrm{C}$, permitindo que tais microrganismos se desenvolvam.

Mesmo com um processo de pausteurização eficiente, o sorvete, sendo um produto derivado do leite, é um ótimo meio de cultura, graças ao elevado valor nutricional, ao $\mathrm{pH}$ quase neutro e à duração do período de armazenamento. A pasteurização não elimina completamente os microrganismos contaminantes, permitindo a sobrevivência de bactérias termo-dúricas não formadoras de esporos e dos esporos da maioria das bactérias, apenas reduzindo o número de microrganismos a níveis aceitáveis. Se houver algum desvio na fase da maturação, com a elevação da temperatura acima de $5^{\circ} \mathrm{C}$, excedendo os limites críticos de tempo/temperatura, poderá ocorrer a multiplicação de microrganismos patogênicos sobreviventes à etapa da pasteurização. Boas práticas após o processamento, incluindo o transporte e a exposição à venda são igualmente importantes. ${ }^{33}$

A análise das características morfotintoriais dos psicrotrófilos aeróbios totais pela coloração de Gram revelou grande diversidade de microrganismos. Bastonetes gram negativos foram os predominantes, sendo estes os principais psicrotrófilos causadores da deterioração do leite e de produtos lácteos pela produção de proteases e lipases. ${ }^{6}$ Os cocos gram positivos mais frequentes como causadores de deterioração de produtos lácteos industrializados são os Micrococcus e Streptococcus, pois são microrganismos resistentes a altas temperaturas e possivelmente sobrevivem à pasteurização. ${ }^{11}$ 
Os bastonetes gram positivos, sobretudo os formadores de esporos, são importantes deterioradores de produtos lácteos processados termicamente. Representantes desse grupo são os Bacillus spp., os quais formam esporos que sobrevivem ao aquecimento. ${ }^{6}$

Em relação aos bastonetes curtos gram positivos, o gênero Listeria, principal representante, é frequentemente associado a produtos lácteos, bem como a outros microrganismos ácido-lácticos, recebendo maior atenção devido aos surtos causados por Listeria monocytogenes. ${ }^{11}$ Degenhardt \& Silva, ${ }^{34}$ ao pesquisarem a presença de Listeria em sorvetes comercializados em sorveterias de autoatendimento, obtiveram positividade em 25,44\% das amostras, sendo 9,8\% pela espécie $L$. monocytogenes. Pooran et al. ${ }^{27}$ e Ambily \& Beena ${ }^{28}$ não detectaram esta bactéria em nenhuma das amostras analisadas.

Leveduras também foram encontradas na coloração de Gram dos psicrotrófilos, sugerindo que é necessário seu controle nos sorvetes, pois algumas espécies têm a capacidade de se desenvolver e deteriorar alimentos com altas concentrações de açúcar. ${ }^{6}$

\section{Conclusões}

Os resultados do presente trabalho demonstraram que há necessidade de maior fiscalização por parte dos órgãos competentes no que se refere a práticas higiênico-sanitárias. Esta necessidade está relacionada à presença, nos sorvetes de massa, de coliformes termotolerantes acima do permitido pela legislação brasileira e de E. coli, microrganismo pertencente à microbiota intestinal de animais de sangue quente.

Mais estudos são necessários para verificar em qual ponto crítico houve falha na higienização, bem como para detectar se a contaminação ocorre durante o processo produtivo ou no ponto de venda.

\section{Referências}

1. Souza J, Costa MR, Rensis CMVB, Sivieri K. Sorvete: composição, processamento e viabilidade da adição de probiótico. Revista Alimentos e Nutrição 2010; 21(1):155-165.

2. Queiroz H, Sampaio Neta NM, Pinto RS, Rodrigues MCP, Costa JMC. Avaliação da qualidade físicoquímica e microbiológica de sorvetes do tipo tapioca. Revista Ciência Agronômica 2009; 40(1):60-65.

3. Cruz A, Antunes AEC, Sousa ALO P, Faria JAF, Saad SMI. Ice cream as a probiotic food carrier. Food Research International 2009; 42(9):1233-1239. 
4. Komatsu TR, Buriti FCA, Saad MI. Inovação, persistência e criatividade superando barreiras no desenvolvimento de alimentos probióticos. Revista Brasileira de Ciências Farmacêuticas 2008; 44(3):329-347.

5. Brasil. Agência Nacional de Vigilância Sanitária. Portaria n. 379, de 26 de abril de 1999. Aprova o regulamento técnico referente a gelados comestíveis, preparados, pós para o preparo e bases para gelados comestíveis. Diário Oficial da União, 29 abr. 1999. [acesso em: 27 set. 2015]. Disponível em: http://portal.anvisa.gov.br/wps/wcm/connect/e824d8804a9bdce99854dc4600696f00/ Portaria_n_379_de_26_de_abril_de_1999.pdf?MOD=AJPERES.

6. JAY JM. Microbiologia de alimentos. 6. ed. Porto Alegre: Artmed; 2005. 712 p.

7. Shrijver K, Buvens G, Possé B, Branden D. Oosterlynck O, Zutter L, et al. Outbreak of verocytotoxinproducing E. coli O145 and O26 infections associated with the consumption of ice cream produced at a farm, Belgium, 2007. Eurosurveillance 2008; 13(7):1-3.

8. Bricio S, Silva C, Finger R. Qualidade bacteriológica do leite pasteurizado tipo C produzido no estado do Rio de Janeiro. Revista brasileira Ciência Veterinária 2005; 12(1-3):124-126.

9. Rosa P, Brum AAS, Orlanda JFF, Sousa HWO. Avaliação das condições higiênico-sanitárias de sorvete produzido artesanalmente no município de Imperatriz - MA. Revista Sorveteria Confeitaria Brasileira 2009;186: 59-62.

10. Brasil. Ministério da Saúde. Resolução RDC No 266, de 22 de setembro de 2005. Regulamento técnico para gelados comestíveis e preparados para gelados comestíveis. Diário Oficial da União, 23 set. 2005. [acesso em: 15 dez. 2012]. Disponível em: http://bvsms.saude.gov.br/bvs/saudelegis/ anvisa/2005/res0266_22_09_2005.html.

11. Franco B, Landgraf M. Microbiologia dos alimentos. São Paulo: Atheneu; 2005.184 p.

12. Kanbakan U, Çon A, Ayar A. Determination of microbiological contamination sources during ice cream production in Denizli, Turkey. Food Control 2004; 15(6):463-470.

13. World Health Organization. Foodborn diseases. health topics [Internet]. [acesso em: 29 set. 2015]. Disponível em: http://www.who.int/topics/foodborne_diseases/en/

14. Kokkinakis E, Fragkiadakis GA, Ioakeimidi SH, Giankoulof IB, Kokkinaki AN. Microbiological quality of ice cream after HACCP implementation: a factory case study. Czech Journal of Food Sciences 2008; 26(5):383-391.

15. American Public Health Association. Committe on microbiologycal methos for foods. Compendiun of Methods for the Microbiologycal Examination of Foods. Washington: Apha; 2001. 676 p.

16. Brasil. Agência Nacional de Vigilância Sanitária. Resolução RDC No 12, de 02 de janeiro de 2001. Regulamento Técnico sobre os padrões microbiológicos para alimentos. Diário Oficial da União, 10 jan. 2001. [acesso em: 03 nov. 2012]. Disponível em: http://www.anvisa.gov.br/legis/resol/12_01rdc.htm

17. Cereser ND, Rossi Jr OD, Marchi PGF, Souza V, Cardozo MV, Martineli TM. Avaliação da qualidade microbiológica da ricota comercializada em supermercados do estado de São Paulo. Ciência Animal Brasileira 2011; 12(1):149-155. 
18. Çağlayanlar G, Kunduhoğlu B, Çoksöyler N. Comparison of the microbiological quality of packed and unpacked ice creams sold in Bursa, Turkey. Journal of Arts and Sciences Sayi 2009; 12:93-102.

19. Baraheem O, El-Shamy H, Bakr W. Bacteriological quality of some dairy products (kariesh cheese and ice cream) in Alexandria. Journal of Egypt Public Health Association 2007; 82(5-6):491-509.

20. Yaman H, Elmaili M, Ulukanli Z, Tuzcu M, Genctav K. Microbial quality of ice cream sold openly by retail outlets in Turkey. Revue de Médecine Vétérinaire 2006; 157(10):457-462.

21. Rizzo-Benato R, Gallo C. Comparação da eficiência dos caldos Escherichia coli e caldo verde brilhante lactose bile na enumeração de coliformes termotolerantes em leite e sorvete de massa. Revista Instituto Adolfo Lutz 2007; 66(1):18-25.

22. World Health Organization. Salmonella. Health Topics [Internet]. [acesso em: 29 set. 2015]. Disponível em: http://www.who.int/topics/salmonella/en/.

23. Center for Disease Control and Prevention. Outbreak of Salmonella enteritidis Associated with Homemade Ice Cream - Florida, 1993. Morbidity and Mortality Weekly Report MMWR 1994; 43(36):669-671.

24. Food and Drug Administration. Center for Food Safety and Applied Nutrition. Enjoying homemade ice cream without the risk of salmonella infection [Internet]. aug. 2004. [acesso em: 29 set. 2015]. Disponível em: http://www.fda.gov/food/foodborneillnesscontaminants/buystoreservesafefood/ ucm332850.htm.

25. Food and Drug Administration. Center for Food Safety and Applied Nutrition. Bulletin to the Food Service and Retail Food Store Industry Regarding Cake Batter Ice Cream and Similar Products [Internet]. 2005. [acesso em: 29 set. 2015]. Disponível em: [http://www.fda.gov/food/ guidanceregulation/retailfoodprotection/industryandregulatoryassistanceandtrainingresources/ ucm114975.htm].

26. Pazianotti L, Bosso AA, Cardoso S, Costa MR, Sivieri K. Características microbiológicas e físicoquímicas de sorvetes artesanais e industriais comercializados na região de Arapongas - PR. Revista Instituto de Laticínios “Cândido Tostes” 2010; 65(377):15-20.

27. Pooran A, Seepersadsingh N, Georges K, Adesiyun AA. Evaluation of the bacteriological quality of ice cream sold in Trinidad. Journal of Food, Agriculture \& Environment 2012; 10(2):39-45.

28. Ambily B, Beena A. Bacteriological quality of ice cream marketed in Thrissur town, Kerala, India. Veterinary World 2012; 5(12):738-741.

29. Vica M, Glevitzky M, Dumitrel GA, Popa M, Todoran A. Microbiological quality of ice-creams produced in Alba County, Romania. Journal of Agroalimentary Oricesses and Technologies 2010; 16(1):19-23.

30. El-Sharef N, Ghenghesh KS, Abognah YS, Gnan SO, Rahouma A. Bacteriological quality of ice cream in Tripoli - Libya. Food Control 2006; 17(8):637-641.

31. Azadnia P, Ghasemi MSA, Abbasi MR, Taarof N, Jashni MK. Microbial quality of traditional ice cream produced by small-scale manufactures in Khormoj and its comparison with the Iranian National Standard. Journal of Animal and Veterinary Advances 2011; 10(6):742-744. 
32. Movassagh MH, Movassagh A, Mahmoodi H, Servatkhah F, Sourorbakhsh MR, et al. Microbiological contamination of the traditional chocolate ice cream sold in the Northwest Region of Iran. Global Veterinaria 2011; 6(3):269-271.

33. Milikita IS, Cândido LMB. Fabricação de sorvetes: Perigos significativos e pontos críticos de controle. Brasil Alimentos 2004; (26):34-37.

34. Degehardt R, Silva F. Pesquisa de Listeria monocytogenes em sorvete expresso e de buffet comercializados na cidade de Joaçaba, Santa Catarina - Brasil. E-Tech: Tecnologias para Competitividade Industrial 2011; 4(1):15-23.

Recebido: $12 / 4 / 2015$

Revisado: 22/9/2015

Aprovado: 27/10/2015 